\title{
Response/comments to maternal paracetamol intake and fetal ductus arteriosus closure: adding pieces to the scenery-Karel Allegaert, Michael Ceulemans, John van den Anke
}

\author{
Manfred Hauben ${ }^{1}$ D $\cdot$ Stephen Bai ${ }^{2} \cdot$ Eric Hung $^{1} \cdot$ Kasia Lobello $^{1} \cdot$ Charles Tressler $^{2} \cdot$ Vincent P. Zucal $^{1}$
}

Received: 16 July 2021 / Accepted: 19 July 2021 / Published online: 26 August 2021

○ The Author(s), under exclusive licence to Springer-Verlag GmbH Germany, part of Springer Nature 2021

\section{Response}

We thank Professor Allegaert et al. for their interest in, and positive comments on, our paper, for reinforcing points we made that cannot be over-emphasized, and for concisely summarizing their recently published fetal-maternal modeling and its implications. Their corresponding hypothesis, that the combined fetal circulatory and placental pharmacodynamic effects of paracetamol are likely to underlie the mechanism of FCCDA, appears plausible. It has been said that "the world was not designed for the convenience of those who frame multiple choice questions"- this is undoubtedly true unless one can "select all that apply" [1].

\section{Reference}

1. Hauben M (2020) QJM: Cover Image 113(3)

Publisher's Note Springer Nature remains neutral with regard to jurisdictional claims in published maps and institutional affiliations.

Manfred Hauben

manfred.hauben@Pfizer.com

Pfizer Inc, New York, NY, USA

2 New York, NY, USA 